\title{
Simplified cholangiography using ioglycamide
}

\author{
G. J. S. PARKIN AND H. HERLINGER \\ From the Departments of Diagnostic Radiology, General Infirmary at Leeds and Leeds (St James's) \\ University Hospital
}

SUMMARY Intravenous cholangiograms were performed on 100 unselected nonicteric patients using methylglucamine ioglycamide (Biligram). Fifty patients received $10.5 \mathrm{~g}$ of contrast medium and 50 received $5.25 \mathrm{~g}$ of medium. The contrast medium was injected evenly over five minutes. Side effects were recorded in only $13 \%$ of patients and all were mild. Radiographs were taken 10, 30, 60,90 , and 120 minutes after injection and were assessed without the authors being aware of the dose of contrast medium injected.

Better statistically significant results were obtained using the higher dose.

In patients in whom the gallbladder is present, films taken at 60 minutes and 90 minutes after injection give the maximum available information in $97 \%$ of cases. If the gallbladder has not become opacified by 60 minutes, cystic duct obstruction is indicated. In postcholecystectomy patients, films at 30 minutes and 60 minutes after injection give the maximum available information in $95 \%$ of cases.

Since its introduction in 1953, iodipamide (Biligrafin) has been used extensively for intravenous cholangiography in this country, and the examination technique has become established (see, for example, Saxton and Strickland, 1972). Ioglycamide is similar to iodipamide in formula (fig 1), but it has some different excretion characteristics which favour a change in the examination routine.

In one of the original papers on ioglycamide, Hoppe in 1964 noted prolonged opacification of the common bile duct. During early trials of the mixed sodium and methylglucamine salts of ioglycamide (Bilivistan) and the pure methylglucamine salt (Biligram), Bell and Braband (1966) and Braband and Ciarkowski (1970) respectively observed that on subjective assessment the best films were obtained 60 minutes after injection.

The present trial was originally designed to determine as objectively as possible the best time for taking films after an injection of the manufacturer's recommended dose of $10.5 \mathrm{~g}$ methylglucamine ioglycamide $(30 \mathrm{ml}$ Biligram for injection). At the Hammersmith Cholangiography Workshop in 1972 it was suggested by Oeser and by Freisig that this dose was in excess of the physiological requirements and that good cholangiograms

Received for publication 30 January 1974.

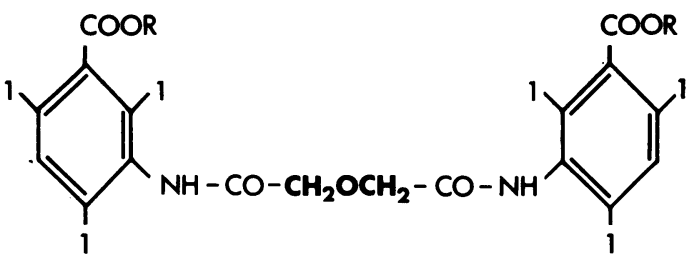

Methylglucamine loglycamide (Biligram)

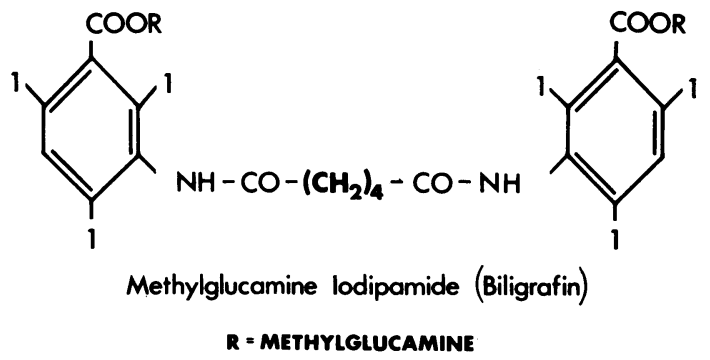

Fig 1 Comparison of chemical formulae of ioglycamide and iodipamide.

should be obtained with lower doses. It was therefore decided to include in the present trial patients injected with only $5.25 \mathrm{~g}$ of ioglycamide $(15 \mathrm{ml}$ Biligram for injection). 


\section{Method}

\section{PATIENTS}

These consisted of 100 consecutive unselected patients presenting for intravenous cholangiography at the two teaching hospitals in Leeds. There were 32 males and 68 females. The age range was 19 to 81 years with a mean of 54 years. Serum bilirubin levels ranged from 0.1 to $2.0 \mathrm{mg} \%$, hence the series is one of non-icteric patients.

\section{EXAMINATION ROUTINE}

After the control film, a sample of blood was taken for liver function tests and then the contrast medium was injected evenly over a period of five minutes timed by the clock. Fifty patients received $10.5 \mathrm{~g}$ ioglycamide (30 ml Biligram for injection) and 50 patients received $5.25 \mathrm{~g}$ ioglycamide (15 ml Biligram for injection). Five minutes later the patient was questioned and any side effects were noted. Initially the question, 'Did the injection cause any unpleasant sensation?' was asked. Any side effects reported were then regarded as 'volunteered'. If the answer was 'no' the patient was questioned specifically about the presence of nausea, urticaria, feeling of faintness, difficulty with breathing, or a metallic taste in the mouth. Side effects elicited in this way were recorded as 'in response to direct questioning'.

Films were taken at 10 minutes and 30 minutes after the end of injection. The patient was then taken off the table and allowed to walk to the waiting room. Further films were taken at 60,90 , and 120 minutes, the patient being taken off the table between films.

\section{Assessment of Radiographs}

The radiographs were assessed by the authors who were unaware of the doses of medium injected. A standard pro forma (fig 2) was completed. All assessments were on straight radiographs and not on the tomograms obtained in some of the cases.

\section{Results}

\section{THE COMMON DUCT}

The best score achieved in each examination is shown in table I.

The scores achieved were significantly better with the higher dose $(P<0.05)$.

Intravenous Cholangiography

Assessment of Radiographs

Name:

X-ray Number :

Examiner:

Trial Number:

\begin{tabular}{|c|c|c|c|c|c|c|c|c|c|c|}
\hline Common Duct & & & & & & $10^{\prime}$ & $30^{\prime}$ & $60^{\prime}$ & $90^{\prime}$ & $120^{\prime}$ \\
\hline 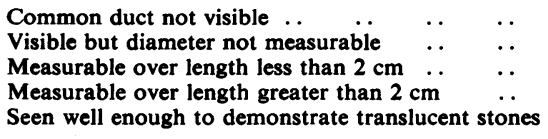 & $\begin{array}{l}\cdots \\
\cdots \\
\cdots \\
\cdots \\
\cdots\end{array}$ & $\begin{array}{l}. . \\
\ddot{.} \\
\ddot{.} \\
\cdots \\
\cdots\end{array}$ & $\begin{array}{l}\because \\
\because \\
\cdots \\
\cdots\end{array}$ & $\begin{array}{l}\cdots \\
\because \\
\cdots \\
\cdots \\
\cdots\end{array}$ & $\begin{array}{l}. . \\
\ddot{.} \\
\ddot{*} \\
\cdots\end{array}$ & $\begin{array}{l}0 \\
1 \\
2 \\
3 \\
4\end{array}$ & $\begin{array}{l}0 \\
1 \\
2 \\
3 \\
4\end{array}$ & $\begin{array}{l}0 \\
1 \\
2 \\
3 \\
4\end{array}$ & $\begin{array}{l}0 \\
1 \\
2 \\
3 \\
4\end{array}$ & $\begin{array}{l}0 \\
1 \\
2 \\
3 \\
4\end{array}$ \\
\hline \multicolumn{11}{|l|}{ Gallbladder } \\
\hline $\begin{array}{l}\text { Not seen } \ldots \\
\text { Seen but not adequate to observe stones } \\
\text { Well shown } . . \\
\text {. . }\end{array}$ & $\begin{array}{l}\cdots \\
\cdots \\
\cdots\end{array}$ & $\begin{array}{l}. \\
\cdots \\
\cdots\end{array}$ & $\begin{array}{l}\cdots \\
\cdots\end{array}$ & $\begin{array}{l}\cdots \\
\cdots \\
\cdots\end{array}$ & $\begin{array}{l}. \\
\cdots \\
\cdots\end{array}$ & $\begin{array}{l}0 \\
1 \\
2\end{array}$ & $\begin{array}{l}0 \\
1 \\
2\end{array}$ & $\begin{array}{l}0 \\
1 \\
2\end{array}$ & $\begin{array}{l}0 \\
1 \\
2\end{array}$ & $\begin{array}{l}0 \\
1 \\
2\end{array}$ \\
\hline
\end{tabular}

Radiological diagnosis

Fig 2 Pro forma used in the assessment of the radiographs. 


\begin{tabular}{lllllll}
\hline $\begin{array}{l}\text { Dose of }(g) \\
\text { Ioglycamide }\end{array}$ & \multicolumn{6}{l}{ Best Score Achieved } \\
\cline { 2 - 7 } & 0 & 1 & 2 & 3 & 4 & Total \\
\hline 10.5 & - & - & 1 & 18 & 31 & 50 \\
5.25 & 6 & 1 & - & 23 & 20 & 50 \\
\hline
\end{tabular}

Table I Best score achieved by common duct in all cases

For a successful examination a score of at least 3 is regarded as essential. If the percentage of cases achieving this score at each time during the examination is plotted, the distribution is as in figure 3 . It is seen that at 60 minutes and 90 minutes after injection at least $95 \%$ of cases receiving the higher dose of contrast medium provide a successful examination of the common duct. Throughout the whole two hours the percentage of successful examinations with the $5.25 \mathrm{~g}$ dose of ioglycamide is lower, and at the 60 minutes and 90 minutes this difference is highly significant $(P<0.005)$.

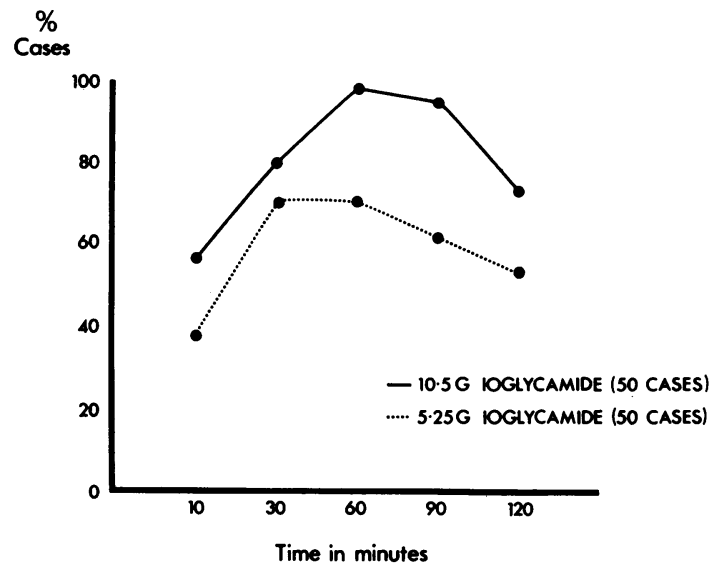

Fig 3 Time of achievement of score of at least ' 3 ' for common duct, ie, a successful cholangiogram.

POSTCHOLECYSTECTOMY PATIENTS

Within the whole series were 22 postcholecystectomy patients. The best score achieved in these patients is shown in table II.

\begin{tabular}{llllll}
\hline \multicolumn{3}{l}{ Best Score Achieved } \\
\hline 0 & 1 & 2 & 3 & 4 & Total \\
\hline 3 & - & - & 3 & 16 & 22 \\
\hline
\end{tabular}

Table II Best score achieved by common duct in postcholecystectomy cases
If the percentage of patients producing a successful examination at each time is plotted, the distribution is shown in figure 4.

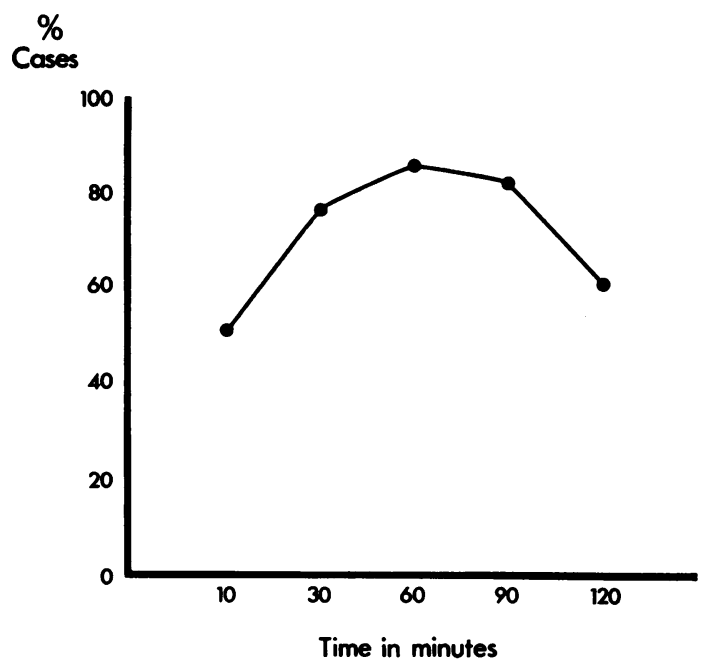

Fig 4 Postcholecystectomy (22 cases). Time of achievement of score of at least ' 3 ' for common duct.

This distribution is similar to that of the whole series shown in figure 3. It can be seen from table II, however, that 16 of the 22 cases achieved a score of 4 . If the percentage of cases achieving the best score at any time, rather than a score of at least 3 is plotted, the distribution is shown in figure 5. From this it can be seen that in these patients the best scores are reflected in films taken at 30 minutes and 60 minutes rather than at 60 minutes and 90 minutes. Indeed, with films at 30 minutes and 60 minutes, the maximum information is obtained in $95 \%$ of patients, but with films at 60 minutes and 90 minutes only $77 \%$ of cases. This difference is statistically significant $(P<0.05)$.

\section{THE GALLBLADDER}

In 78 patients the gallbladder was present. The best score achieved for the gallbladder is shown in table III.

Where any opacification of the gallbladder occurs a score of 2 is essential to render the examination adequate. Hence in 37 out of 44 cases ( $84 \%$ ), the examination of the gallbladder using ioglycamide was regarded as successful. There was no statistical difference in the incidence of successful examinations with the two contrast medium dosages.

In 34 cases the gallbladder was not opacified. In 


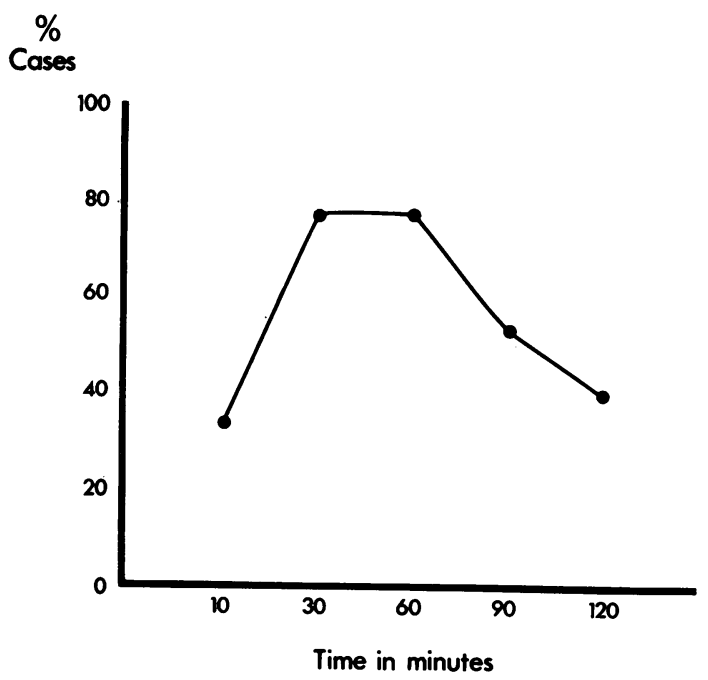

Fig 5 Postcholecystectomy (22 cases). Time of achievement of best score for common duct.

\begin{tabular}{lllll}
\hline $\begin{array}{l}\text { Dose of } \\
\text { Ioglycamide } \\
(g)\end{array}$ & \multicolumn{3}{l}{ Best Score Achieved } \\
\cline { 2 - 5 } & 0 & 1 & 2 & Total \\
\hline 10.5 & 10 & 4 & 22 & 36 \\
$5 \cdot 25$ & 24 & 3 & 15 & 42 \\
Total & 34 & 7 & 37 & 78 \\
\hline
\end{tabular}

Table III Best score achieved by gallbladder

four of these cases (all having received the lower dose of contrast medium), neither gallbladder nor ducts were opacified, ie, they were failed examinations. In the other 30 cases the ducts were opacified but not the gallbladders. Of these 30 cases, 16 have so far come to operation and all were found to have pathological gallbladders with obstructed cystic ducts.

In all cases where any opacification of the gallbladder occurred, there was some contrast medium detectable in the gallbladder on the 60-minute film. This, together with the above-mentioned operative findings, suggests that it is feasible to diagnose cystic duct obstruction on intravenous cholangiography using ioglycamide without having to prolong the examination.

If the times of achieving the best score for common duct and gallbladder are plotted together (fig 6) it is seen that the films at 60 minutes and 90 minutes after injection provide the maximum information just as had been found when considering the common duct alone (fig 3). Using the higher dose a

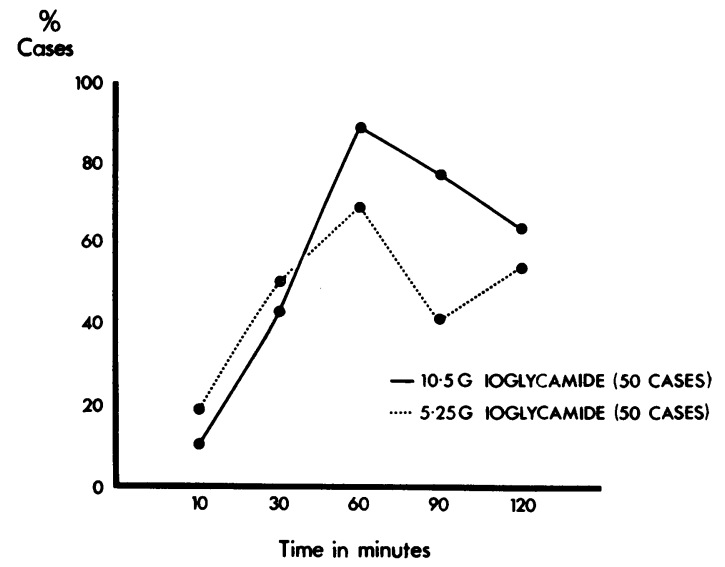

Fig 6 Time of achievement of best combined score for common duct and gallbladder.

single film at 60 minutes after injection provides the best obtainable score (and hence the most information) in $89 \%$ of cases, and the addition of a further film at 90 minutes increases this to $97 \%$.

\section{SIDE EFFECTS}

The nature and incidence of side effects is shown in table IV.

\begin{tabular}{|c|c|c|}
\hline \multirow[t]{2}{*}{ Side Effect } & \multicolumn{2}{|c|}{ Number of Affected Patients } \\
\hline & Volunteered & Direct Questioning \\
\hline $\begin{array}{l}\text { Urticaria } \\
\text { Nausea } \\
\text { Metallic taste in mouth } \\
\text { Total }\end{array}$ & $\begin{array}{l}2 \\
2 \\
4\end{array}$ & $\begin{array}{c}\overline{1} \\
4\end{array}$ \\
\hline
\end{tabular}

Table IV Nature and incidence of side effects

The overall incidence of side effects is therefore $13 \%$ but all were mild. The most serious, the two cases of urticaria, responded well to $10 \mathrm{mg} \mathrm{i} / \mathrm{m}$ chlorpheniramine maleate and had completely resolved by the time the patients left the department just over two hours after the injection of contrast medium. It is noteworthy that not a single patient vomited during or after the injection.

Such a low incidence of mild side effects is worthy of note, when the main advantage claimed for the more time-consuming, more expensive technique of infusion cholangiography is the low incidence of side effects (Moss, Nelson, and Amberg, 1973). 


\section{Conclusions}

A dose of $10.5 \mathrm{~g}$ ioglycamide (30 ml Biligram for injection) produces statistically better results than half that dose. It is therefore recommended that the higher dose be employed.

In patients in whom the gallbladder is present, films at 60 minutes and 90 minutes after injection will provide the maximum information available from the examination in $97 \%$ of cases.

In patients with an intact gallbladder, if no opacification of the gallbladder has occurred by 60 minutes, the presence of cystic duct obstruction and a pathological gallbladder is indicated.

In the postcholecystectomy patients films at 30 minutes and 60 minutes after injection provide the maximum information available from the examination in $95 \%$ of cases.

With the injection technique employed here side effects are few and those that do occur are mild.

A simplified procedure for intravenous cholangiography can therefore be advanced: (a) control film; (b) injection of $10.5 \mathrm{~g}$ ioglycamide $(30 \mathrm{ml}$ Biligram for injection) evenly over five minutes; (c) in patients with the gallbladder present, two films taken at 60 minutes and 90 minutes after injection, the patient being taken from the radiographic couch between films; in postcholecystectomy patients the films should be taken 30 minutes and 60 minutes after injection.

Utilization of the radiographic room is not essential for the whole procedure, as the injection can be given in an anteroom, and the complete examination takes less than 10 minutes with the patient on the table.

The authors thank their colleagues for assistance in performing the examinations, and the Department of Medical Illustration at Leeds (St James's) University Hospital for producing the figures.

Messrs Schering kindly provided the Biligram used in this trial.

\section{References}

Bell, H. D. C., and Braband, H. (1966). Bilivistan-a new contrast medium for intravenous cholangiocystography. Brit. J. Radiol., 39, 63-65.

Braband, H., and Ciarkowski, J. (1970). Klinische Prüfung eines verbesserten Kontrastmittels zür intravenösen Cholangiozystographie. Röntgenpraxis, 23, 86-94.

Hoppe, G. (1964). Das positive Cholangiogramm als Wertmassstmab für Gallenkontrastmittel. Fortschr. Rontgenstr., 100, 520-524.

Moss, A. A., Nelson, J., and Amberg, J. (1973). Intravenous cholangiography: an experimental evaluation of several currently proposed methods. Amer. J. Roentgenol., 117, 406-411.

Saxton, H. M., and Strickland, B. (1972). Practical Procedures in Diagnostic Radiology, 2nd ed. Lewis, London. 